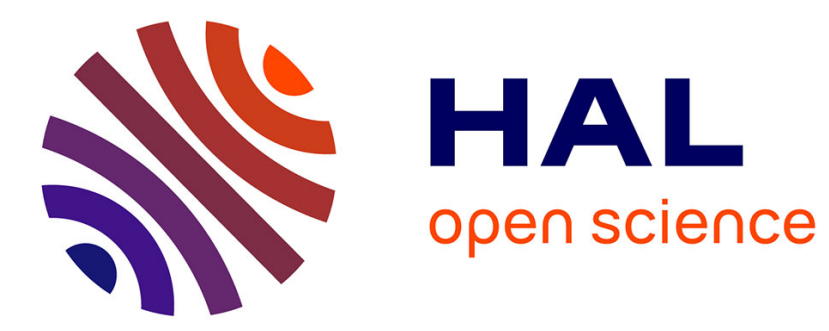

\title{
Why is bis-indenylchromium a dimer? A DFT investigation
}

Bachir Zouchoune, Saber-Mustapha Zendaoui, Jean-Yves Saillard

\section{To cite this version:}

Bachir Zouchoune, Saber-Mustapha Zendaoui, Jean-Yves Saillard. Why is bis-indenylchromium a dimer? A DFT investigation. Journal of Organometallic Chemistry, 2018, 858, pp.47-52. 10.1016/j.jorganchem.2017.12.035 . hal-01737389

HAL Id: hal-01737389

\section{https://hal-univ-rennes1.archives-ouvertes.fr/hal-01737389}

Submitted on 18 May 2018

HAL is a multi-disciplinary open access archive for the deposit and dissemination of scientific research documents, whether they are published or not. The documents may come from teaching and research institutions in France or abroad, or from public or private research centers.
L'archive ouverte pluridisciplinaire HAL, est destinée au dépôt et à la diffusion de documents scientifiques de niveau recherche, publiés ou non, émanant des établissements d'enseignement et de recherche français ou étrangers, des laboratoires publics ou privés. 


\title{
Why is Bis-Indenylchromium a Dimer? A DFT Investigation
}

Bachir Zouchoune, ${ }^{\mathrm{a}, \mathrm{b} *}$ Saber-Mustapha Zendaoui ${ }^{\mathrm{a}, \mathrm{b}}$ and Jean-Yves Saillard ${ }^{\mathrm{c}^{*}}$

${ }^{a}$ Unité de Recherche en Chimie de l'Environnement et Moléculaire Structurale, Université Mentouri-Constantine, (25000) Constantine, Algeria

${ }^{b}$ Laboratoire de Chimie Appliquée et Technologie des Matériaux, Université Larbi Ben M'HidiOum-el-Bouaghi, 04000 Oum-el-Bouaghi, Algeria

${ }^{c}$ UMR 6226-Institut des Sciences Chimiques de Rennes, CNRS-Université de Rennes 1, Campus de Beaulieu, 35042 Rennes-Cedex, France

Emails: bzouchoune@gmail.com and saillard@univ-rennes1.fr

\begin{abstract}
Unsubstituted bis-indenylchromium has been shown to be a dimer, $\mathrm{Cr}_{2}(\operatorname{Ind})_{4}$, whereas the monomeric sandwich-type structure, $\mathrm{Cr}(\mathrm{Ind})_{2}$, has been only observed for substituted relatives. DFT calculations indicate that dimerization allows the building of a quadruple $\mathrm{Cr}-\mathrm{Cr}$ bond whereas it can still participate in five formal 2-electron metal-ligand bonds. Despite of this apparently favorable situation with respect to dimer stability, the energetic balance in favor of the dimer is computed not to be very large. Calculations on a series of related $\mathrm{Cr}, \mathrm{Mn}, \mathrm{Fe}$ and Co relatives indicate that $\mathrm{Cr}_{2}(\mathrm{Ind})_{4}$ appears unique in terms of its stability relatively to its monomer. However, dimeric species such as $\mathrm{Cr}_{2}(\mathrm{Cp})_{2}(\mathrm{Ind})_{2}, \mathrm{Cr}_{2}(\mathrm{Cp})_{4}$ or $\mathrm{Mn}_{2}(\mathrm{Ind})_{4}$ appear to be not that much unstable relatively to their monomer for being observed under some specific circumstances.
\end{abstract}




\section{Introduction}

Indenylide, $\left(\mathrm{C}_{9} \mathrm{H}_{7}\right)^{-}$, can be viewed as a substituted cyclopentadienyl anion (Lewis structure I in Scheme 1), although, as a ligand in organometallic complexes, it can induce properties which can be quite different from those of their regular cyclopentadienyl relatives [1], due to significant contribution of Structure II which emphasizes the somewhat allylic character of the 5-fold ring. From this point of view, the bis-indenyl complexes of first-row transition-metals have fairly different properties (including sometimes spin states) as their metallocene analogues [2-9]. The case of chromium is even more puzzling since sandwich-type bis-indenyl chromium complexes exist only with substituted indenyl ligands [4,5], the unsubstituted species being a dimer [10]. The structure of $\mathrm{Cr}_{2}(\mathrm{Ind})_{4}$, (Ind = indenyl) is sketched in Scheme 2 and shown in Figure 1, Because of steric congestion, it has a somehow unsymmetrical structure and exhibits two $\eta^{5}$-Ind and two $\mu, \eta^{3}$-Ind ligands. From its compact nature, one can understand that the presence of substituents on the indenyl ligands might disfavor dimerization. Considering the ligands as formally monoanionic (indenylides), $\left(\eta^{5} \text {-Ind) }\right)^{-}$and $\left(\eta^{3} \text {-Ind) }\right)^{-}$are 6- and a 4-electron donors, respectively. Thus, in this molecule, each $\mathrm{Cr}(\mathrm{II})$ atom receives 6 electrons from one $\eta^{5}$-indenylide and 2 electrons from each of the two bridging $\eta^{3}$-indenylide it is bonded to. There is no mention in the original paper of Jolly and coworkers about the magnetic behavior of $\mathrm{Cr}_{2}(\mathrm{Ind})_{4}[10]$ but the comments of these authors on an apparently normal ${ }^{13} \mathrm{C}$ NMR spectrum, suggest it is diamagnetic. Assuming diamagnetism, a metal-metal quadruple bond can be expected if the 18-electron rule is satisfied, and actually the value of the observed intermetallic distance $(2.175(1) \AA$ ) [10] does not contradict this hypothesis [11].
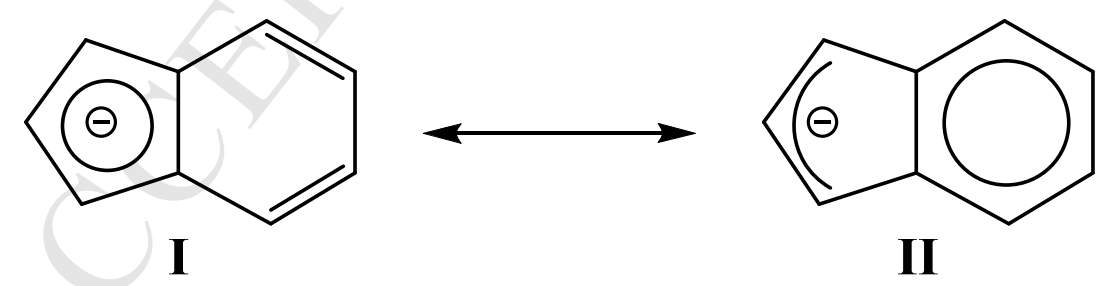

Scheme 1. Major Lewis structures of the indenyl anion.

As noted by Jolly and coworkers [10], the structure of $\mathrm{Cr}_{2}\left(\eta^{5}-\mathrm{Ind}\right)_{2}\left(\mu-\eta^{3}-\mathrm{Ind}\right)_{2}$ is related to that of $\mathrm{Cr}_{2}\left(\eta^{5}-\mathrm{Ind}\right)(\mu-\mathrm{Cl})\left(\mu-\eta^{3}\right.$-Ind) [10] and $\mathrm{Cr}_{2}\left(\eta^{5} \text {-Ind }\right)_{2}\left(\mu-\eta^{3} \text {-allyl }\right)_{2}$ [12] (see Scheme 2 and Figure 1). The cyclopentadienyl analog of the latter, $\mathrm{Cr}_{2}\left(\eta^{5}-\mathrm{Cp}\right)_{2}\left(\mu, \eta^{3} \text {-allyl }\right)_{2}$, exists also (Scheme 
2 and Figure 1). [12] In these three complexes, the bridging chloride or allyl anions are 4-electron donor ligands, similarly to the $\mu, \eta^{3}$-indenylide ligand in $\mathrm{Cr}_{2}(\mathrm{Ind})_{4}$. Their $\mathrm{Cr}-\mathrm{Cr}$ distance is equal to 2.317(1) $\AA^{10}{ }^{10} 2.171(1) / 2.198(1) \AA[12,13]$ and 2.299(1) $\AA$ [12], respectively.

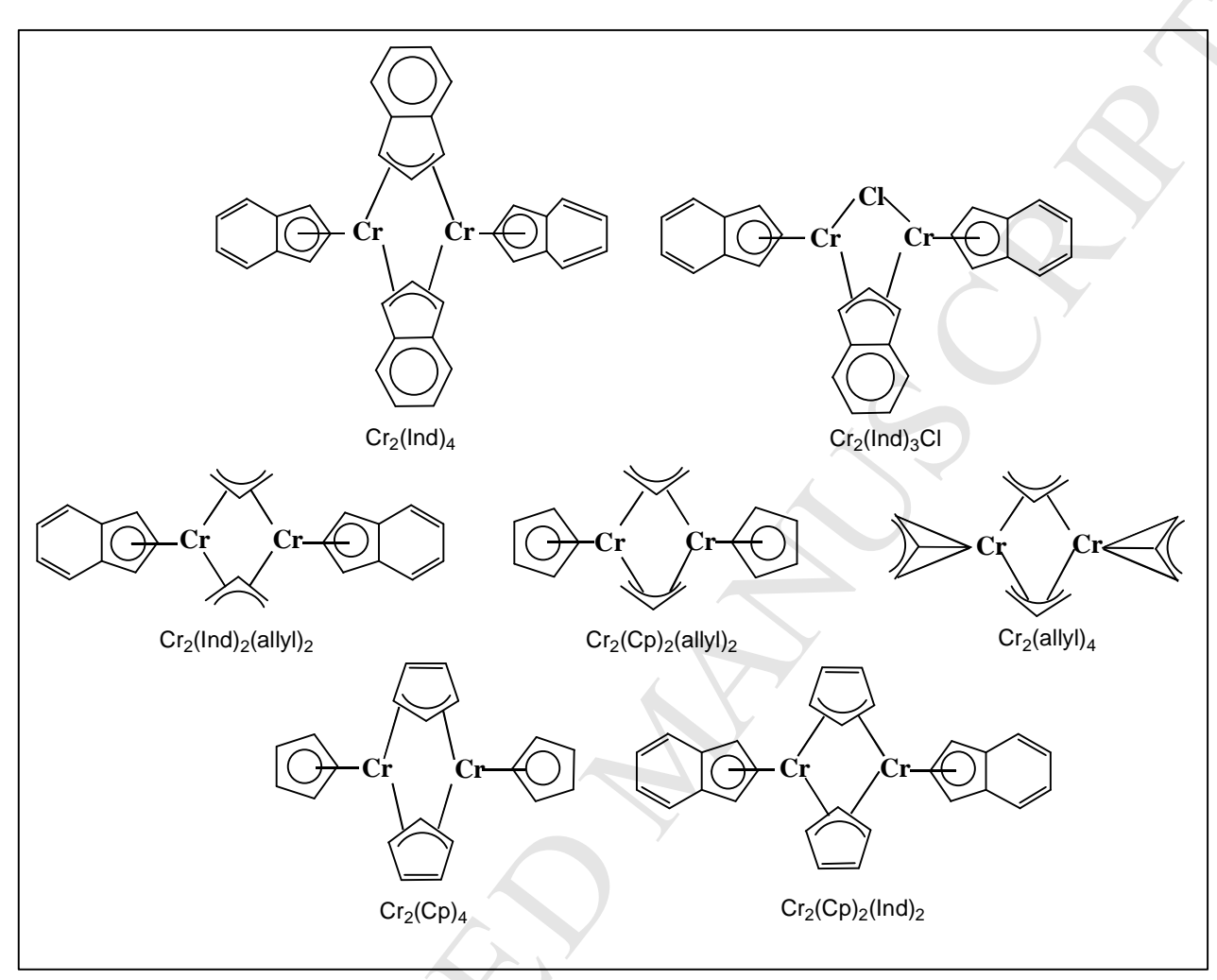

Scheme 2. Planar sketches of the discussed chromium compounds. The metal-metal bond (quadruple in the singlet state) is not represented.

Thus, in these dimers, the existence of a quadruple bond between two 18-electron $\mathrm{Cr}$ (II) centers cannot be ruled out, although the metal-metal separations in the former and latter are more consistent with the existence of a lower bond order [11]. On the other hand, $\mathrm{Cr}_{2}\left(\eta^{3}-\text { allyl }\right)_{2}\left(\mu-\eta^{3}-\right.$ allyl) $)_{2}$ exists also [14] and has a related structure (Scheme 2 and Figure 1) with a Cr-Cr distance of 1.97(6) A. [14b] Since the allyl anion is a 4-electron donor, $\mathrm{Cr}_{2}(\text { allyl })_{4}$ bears 4 electron less than $\mathrm{Cr}_{2}(\mathrm{Ind})_{4}$ and cannot satisfy the 18 -electron rule, even assuming a metal-metal quadruple bond. Nevertheless, quadruply bonded 16-electron dinuclear complexes are not scarce [11]. Among all these complexes more or less related to $\mathrm{Cr}_{2}\left(\eta^{5}-\mathrm{Ind}\right)_{2}\left(\mu-\eta^{3}-\mathrm{Ind}\right)_{2}$, only $\mathrm{Cr}_{2}\left(\eta^{5}-\mathrm{Cp}\right)_{2}\left(\mu, \eta^{3} \text {-allyl }\right)_{2}$ $[12,15]$ is described as paramagnetic, with a magnetic moment of $4.1 \mu_{\mathrm{B}}$ determined under experi- 
mental conditions which do not exclude the presence of magnetic impurities [12]. All the other above-mentioned dichromium complexes are likely to be diamagnetic.

In order to understand the dimeric nature of $\mathrm{Cr}(\operatorname{Ind})_{2}$ and to get a better insight in its spin state and bonding situation, as well as in the related compounds mentioned above, we have undertaken a density functional theory (DFT) investigation on the above-mentioned dimers. We also investigated the possibility for other $\mathrm{M}(\mathrm{Ind})_{2}$ complexes to dimerize, as well as that of simple metallocenes.
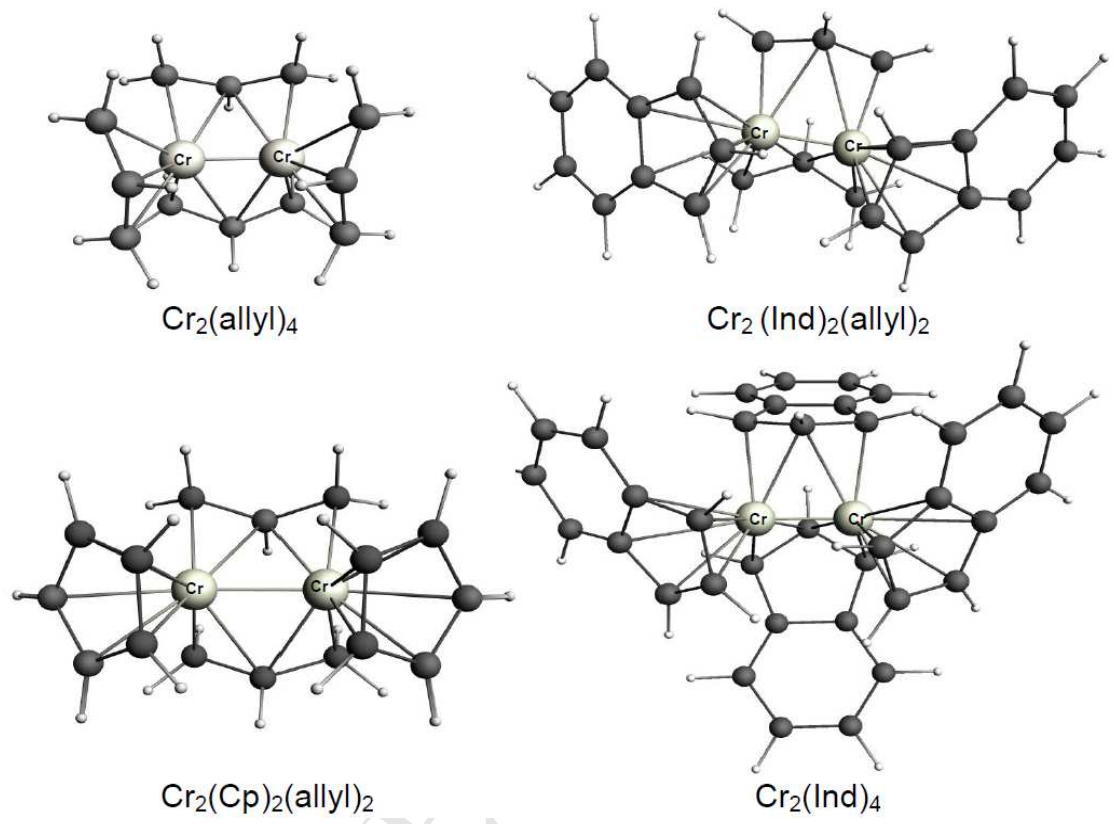

Figure 1. Molecular structures of the four experimentally characterized dimers. [10,12]

\section{Computational Details}

The quantum chemical description of the metal-metal interaction in multiply bonded dinuclear chromium complexes is not always straightforward and it is known that the best approach for such systems is by using a multiconfigurational method [16]. However, the use of such timeconsuming approaches is restricted to complexes of rather small size and cannot be applied to series of transition-metal complexes. On the other hand, although density functional theory (DFT) has limitations related to its monodeterminantal nature, recent calculations have proven to be able to provide a description of $\mathrm{Cr}-\mathrm{Cr}$ bonding at a reasonably high level of accuracy [17]. This is why we have chosen this method for carrying out our investigation. All the calculations were performed with the 2010.01 version of the Amsterdam Density Functional (ADF) program developed by Baer- 
ends and co-workers [18]. Assuming the Vosko-Wilk-Nusair parametrization for the local density approximation. [19] Because several spin states were likely to compete in the computed complexes, we have first tested three different non-local corrections, namely the GGA BP86 functional [20], which is known for its tendency for overestimating the low-spin state stability, the B3LYP hybrid functional [21], which usually overestimates the high-spin state stability, and the related B3LYP* functional [22]. This latter functional contains less Hartree-Fock contribution than B3LYP and therefore is in principle better suited for providing correct spin-state orderings. A systematic structural discrepancy was found between the results computed with these three functionals and the Xray structures of the compounds containing terminal indenyl ligands. Whereas the experimental structures exhibit a typical unsymmetrical $\eta^{5}$-Ind coordination mode with three shorter $(\sim 2.2-2.3$ $\AA$ ) and two longer ( 2.4-2.5 $\AA$ ) Cr-C bonds, the corresponding optimized values of the longer bonds were found somewhat overestimated ( 2.6-2.7 $\AA$ ). Owing to the compactness of the investigated molecules, an overestimation of steric congestion was suspected so that it was decided to take into account dispersion forces by using the Grimme empirical corrections [23] through the use of the BP86-D and B3LYP-D functionals which are implemented in the ADF code. It was found that employing these functionals almost cancelled the above-mentioned discrepancy with the experimental structures found with the non-corrected functionals. In summary, the five above-mentioned functionals were used to carry out full geometry optimizations of different spin states of the considered chromium complexes.

The standard ADF TZP basis set was used, i.e., a triple- $\xi$ Slater-type orbital basis set for the valence shells, augmented with single- $\xi$ polarization functions $(2 \mathrm{p}$ for $\mathrm{H}, 3 \mathrm{~d}$ for $\mathrm{C}, 4 \mathrm{p}$ for the firstrow metals) [18]. The BP86 and BP86-D calculations were performed assuming the frozen-core approximation [18] up to $1 \mathrm{~s}$ for $\mathrm{C}$ and $3 \mathrm{p}$ for the first-row metals. Spin-unrestricted calculations were performed for all the open-shell systems. The analytical gradient method developed by Versluis and Ziegler [25] was used in the calculations. When X-ray structures were available, they were used as starting geometries in the optimizations processes. The $\mathrm{Cr}_{2}(\mathrm{Cp})_{4}$ and $\mathrm{Cr}_{2}(\mathrm{Cp})_{2}(\mathrm{Ind})_{2}$ starting geometries were derived from the X-ray structure of $\mathrm{Cr}_{2}(\mathrm{Ind})_{4}$. Only the $\mathrm{Cr}_{2}(\operatorname{allyl})_{4}$ and $\mathrm{Cr}_{2}(\mathrm{Cp})_{2}(\text { allyl })_{2}$ dimers were found to possess a symmetry element, i.e a mirror plane connecting the two $\mathrm{Cr}$ atoms $\left(C_{s}\right.$ symmetry). All the other investigated compounds were found to be slightly unsymmetrical. Vibrational frequency calculations [26] were performed on all the optimized geometries which were ascertained as energy minima by the non-existence of imaginary frequencies. All 
the energy values reported in this paper include zero-point energy (ZPE) correction. Dissociation energies have been corrected from basis set superposition error (BSSE) with the counterpoise method. The relative enthalpy values $(\Delta \mathrm{G})$ are computed for room temperature. They show similar trends as their ZPE-corrected total energy counterparts $(\Delta \mathrm{E})$ which are provided as supplementary information (SI) material. Representations of the orbitals and of the molecular structures were done by using the ADF-GUI [18] and the MOLEKEL4.1 [27] programs, respectively. The natural population-based and Wiberg bond indices (NPAI and WBI, respectively) [28] were obtained from calculations implemented in the NBO 6.0 program [29].

\section{Energetic and structural results of the chromium complexes}

The experimentally characterized complexes $\mathrm{Cr}_{2}(\text { allyl })_{4}, \mathrm{Cr}_{2}(\mathrm{Cp})_{2}(\text { allyl })_{2}, \mathrm{Cr}_{2}(\mathrm{Ind})_{2}(\text { allyl })_{2}$ and $\mathrm{Cr}_{2}(\mathrm{Ind})_{4}$ have been computed, together with the hypothetical compounds $\mathrm{Cr}_{2}(\mathrm{Cp})_{2}(\mathrm{Ind})_{2}$ and the dimer of chromocene, namely $\mathrm{Cr}_{2}(\mathrm{Cp})_{4}$. In the case of $\mathrm{Cr}_{2}(\mathrm{Cp})_{2}(\mathrm{Ind})_{2}$, only the significantly more stable isomer, namely $\mathrm{Cr}_{2}\left(\eta^{5}-\mathrm{Cp}\right)_{2}\left(\mu-\eta^{3}-\mathrm{Ind}\right)_{2}$, is considered in this paper. Their major energetic results (are reported in Table 1 (relative free energies, $\Delta \mathrm{G}$ ) and Table $\mathrm{S} 1$ (relative energies, $\Delta \mathrm{E})$ for all the functionals and spin states considered. The $\Delta \mathrm{G}$ and $\Delta \mathrm{E}$ values relatively to the corresponding monomeric species in their lowest spin state are also reported. All the computed $\Delta \mathrm{G}$ and $\Delta \mathrm{E}$ series follow the same trends. One can see that B3LYP and B3LYP-D calculations found all the complexes to have a triplet ground state. The same spin state ordering is found with B3LYP* but, as expected the corresponding energy difference is reduced. The BP86 and BP86-D results favour singlet ground states except for $\mathrm{Cr}_{2}(\mathrm{Cp})_{2}(\text { allyl })_{2}$ for which a triplet ground state is slightly preferred. If one assumes that all the experimentally characterized compounds are likely to be diamagnetic, except for $\mathrm{Cr}_{2}(\mathrm{Cp})_{2}(\text { allyl })_{2}$ (see above), one reaches the conclusion that, from the energetic point of view, the GGA results appear more reliable for this particular series of compounds.

$\mathrm{Cr}_{2}$ (Ind) $)_{4}$ is found to be stable with respect to dissociation in two chromium bis-indenyl monomers, in full agreement with experiment (Table 1) [10]. On the other hand, the hypothetical $\mathrm{Cr}_{2}\left(\eta^{5}-\mathrm{Cp}\right)_{2}\left(\mu, \eta^{3} \text {-allyl }\right)_{2}$ and $\mathrm{Cr}_{2} \mathrm{Cp}_{4}$ dimers are found to be unstable with respect to dissociation. From the structural point of view, the $\mathrm{Cr}-\mathrm{Cr}$ distances computed for the triplet states are closer to the X-ray values than the singlet state ones (Table 2). However, it is known that DFT tends to overestimate the distance between multiply bonded chromium atoms [16a]. A somewhat better overall 
agreement with $\mathrm{X}$-ray is also found for the $\mathrm{Cr}$ - $\mathrm{C}$ distances computed for the triplet state, but it is difficult to conclude owing to the large dispersion and low accuracy of the experimental values.

Table 1. Computed singlet/triplet free energy differences (in $\mathrm{kcal} / \mathrm{mol}$ ) of the investigated dinuclear chromium complexes and their free dissociation energy (formation of monomers; BSSE considered).

\begin{tabular}{|c|c|c|c|c|c|c|c|c|}
\hline & $\mathrm{Cr}_{2}(\text { allyl })_{4}$ & $\mathrm{Cr}_{2}(\mathrm{Cp})_{2}(\text { allyl })_{2}$ & $\mathrm{Cr}_{2}(\text { Ind })_{2}(\text { allyl })_{2}$ & $\mathrm{Cr}_{2}(\mathrm{Ind})_{4}$ & \multicolumn{2}{|c|}{$C r_{2}(C p)_{2}(\text { Ind })_{2}$} & \multicolumn{2}{|c|}{$\mathrm{Cr}_{2}(\mathrm{Cp})_{4}$} \\
\hline $\begin{array}{c}\text { Exp. magnetic } \\
\text { behavior }\end{array}$ & diamagnetic $^{a}$ & paramagnetic $^{a}$ & diamagnetic $^{a}$ & diamagnetic $^{a}$ & & & & \\
\hline & $\Delta G_{S / T}^{b}$ & $\Delta G_{S / T}$ & $\Delta G_{S / T}$ & $\begin{array}{l:l}\Delta G_{S / T} & \Delta G_{\text {Diss }}{ }^{c}\end{array}$ & $\Delta G_{S / T}$ & $\Delta G_{D i s s}$ & $\Delta G_{S / T}$ & $\Delta G_{D i s s}$ \\
\hline$B 3 L Y P$ & +6.1 & +26.3 & +17.9 & +8.4 & +9.4 & -5.9 & +17.1 & -10.6 \\
\hline$B 3 L Y P^{*}$ & +1.4 & +15.6 & +10.4 & $\begin{array}{c:c}+8.3 & +4.1\end{array}$ & +6.4 & -3.6 & +12.8 & -10.5 \\
\hline$B 3 L Y P-D$ & +9.6 & +22.1 & +15.3 & $\begin{array}{l:l}+7.9 & +9.2 \\
\end{array}$ & +8.9 & -6.4 & +16.8 & -6.7 \\
\hline BP86 & -16.2 & +4.2 & -7.4 & +5.6 & -7.1 & -4.1 & +1.3 & -2.0 \\
\hline$B P 86-D$ & -7.6 & +1.0 & -8.7 & \begin{tabular}{l|l}
-8.2 & +8.9
\end{tabular} & -3.2 & -7.0 & +1.7 & -8.1 \\
\hline
\end{tabular}

${ }^{\mathrm{a}}$ Presumed magnetic behavior (from refs 10, 12 and14, see text).

${ }^{\mathrm{b}} \Delta \mathrm{G}_{\mathrm{S} / \mathrm{T}}=\mathrm{G}($ singlet $)$ - G(triplet) (in $\left.\mathrm{kcal} / \mathrm{mol}\right)$. A negative value means singlet ground state.

${ }^{c} \Delta \mathrm{G}_{\text {Diss }}=2 \times \mathrm{G}$ (monomer ground state $)-\mathrm{G}$ (dimer ground state) (in kcal $\left./ \mathrm{mol}\right)$. A negative value means that the compound is more stable in its monomer form.

\section{Bonding analysis of the chromium complexes}

In the followings, the bonding in the singlet states is first analysed. The results which are commented below are taken from the BP86-D calculations. In the case of the $\mathrm{Cr}_{2}\left(\eta^{3} \text {-allyl }\right)_{2}\left(\mu, \eta^{3}\right.$ allyl $)_{2}$, the ligand environment of each $\mathrm{Cr}$ (II) center can be roughly approximated to square planar. Thus, $\mathrm{Cr}_{2}\left(\eta^{3} \text {-allyl }\right)_{2}\left(\mu, \eta^{3} \text {-allyl }\right)_{2}$ can be related for example to the family of the $D_{4 h} \mathrm{Cr}_{2}\left(\mathrm{CO}_{2} \mathrm{R}\right)_{4}$ complexes in which the $\mathrm{Cr}$ (II) atoms are bridged by four carboxylate ligands and lying in a local square planar $\mathrm{CrO}_{4}$ ligand environment [11a]. Such complexes are known for exhibiting a quadruple bond between the two 16-electron metals and indeed, this is also the case for $\mathrm{Cr}_{2}\left(\eta^{3}\right.$ allyl $)_{2}\left(\mu, \eta^{3} \text {-allyl }\right)_{2}$, the Kohn-Sham orbital diagram of which is shown in Figure 2. It clearly exhibits four occupied metal-metal bonding orbitals which, despite of some $\sigma / \pi / \delta$ mixing due to the low molecular symmetry, can be identified as the $\sigma, \pi_{\perp}, \pi_{/ /}$and $\delta$ components of the metal-metal bond. Unsurprisingly, the LUMO is the $\delta^{*}$ orbital. It lies $1.65 \mathrm{eV}$ below the LUMO+1, preventing the 
existence of a low-lying excited quintuplet state. The BP86-D NPA Cr-Cr bond index (3.3, see Table 2) is fully consistent with the existence of a quadruple bond, the corresponding Wiberg index being, as expected, lower (2.5).

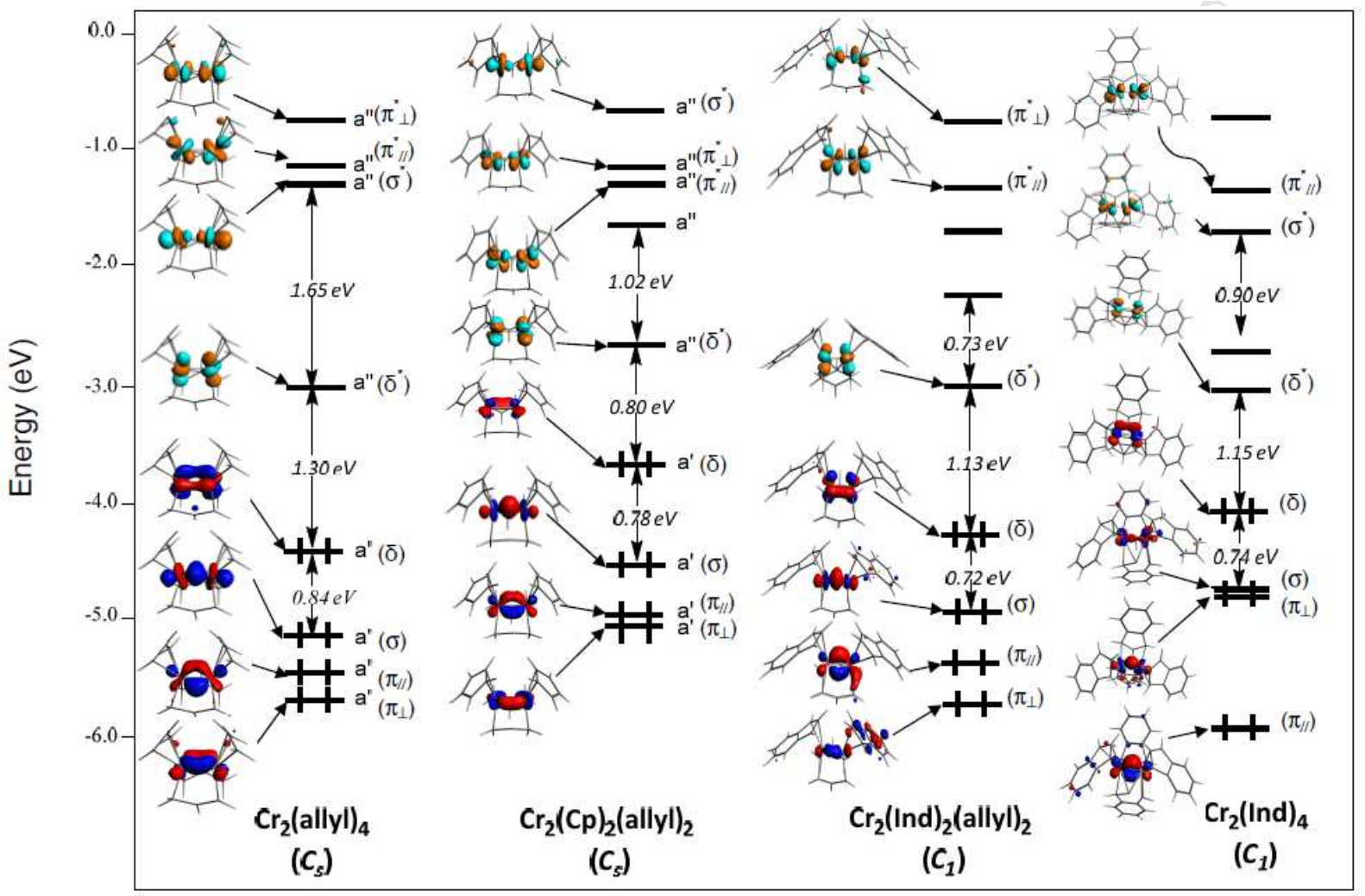

Figure 2. Kohn-Sham orbital diagrams obtained by BP86-D calculations on the singlet states of different dichromium complexes.

Going from $\mathrm{Cr}_{2}\left(\eta^{3} \text {-allyl }\right)_{2}\left(\mu, \eta^{3} \text {-allyl }\right)_{2}$ to $\mathrm{Cr}_{2}\left(\eta^{5}-\mathrm{Cp}\right)_{2}\left(\mu, \eta^{3} \text {-allyl }\right)_{2}, \mathrm{Cr}_{2}\left(\eta^{5} \text {-Ind }\right)_{2}\left(\mu, \eta^{3} \text {-allyl }\right)_{2}$ or $\mathrm{Cr}_{2}\left(\eta^{5} \text {-Ind }\right)_{2}\left(\mu, \eta^{3} \text {-Ind }\right)_{2}$ consists in formally adding a supplementary terminal 2-electron ligand on each metal. Therefore these three complexes can be related to the family of the $D_{4 h} \mathrm{Cr}_{2}\left(\mathrm{CO}_{2} \mathrm{R}\right)_{4} \mathrm{~L}_{2}$ ( $\mathrm{L}=$ terminal 2-electron ligand) in which the $\mathrm{Cr}(\mathrm{II})$ atoms reach the 18-electron count by making a quadruple bond between them [11a]. This is exemplified by their Kohn-Sham orbital diagrams (Figure 2) and their computed NPA and Wiberg Cr-Cr bond indices (Table 2). The lower computed HOMO/LUMO gap of $\mathrm{Cr}_{2}\left(\eta^{5}-\mathrm{Cp}\right)_{2}\left(\mu, \eta^{3} \text {-allyl }\right)_{2}$ is consistent with the near degeneracy of its singlet and triplet states at the BP86-D level. Its quintuplet state is found in a higher energy. The other 
computed dimers, namely the hypothetical $\mathrm{Cr}_{2} \mathrm{Cp}_{2}(\mathrm{Ind})_{2}$ and $\mathrm{Cr}_{2} \mathrm{Cp}_{4}$, have similar electronic structure (see Table 2 and Figure S1). In all the computed dimers, the triplet state corresponds to the expected $(\delta)^{1}\left(\delta^{*}\right)^{1}$ configuration and the $\mathrm{Cr}-\mathrm{Cr}$ bond order decreases to 3 .

Table 2. Experimental and computed $\mathrm{Cr}-\mathrm{Cr}$ bond lengths (BL, in $\AA$ ) of the chromium species and corresponding computed NPA and Wiberg bond indices (NPAI and WI, respectively; see Computational Details).

\begin{tabular}{|c|c|c|c|c|c|c|c|c|c|c|c|c|c|}
\hline & & \multicolumn{2}{|c|}{$\mathrm{Cr}_{2}(\text { allyl })_{4}$} & \multicolumn{2}{|c|}{$\mathrm{Cr}_{2}(\mathrm{Cp})_{2}(\text { allyl })_{2}$} & \multicolumn{2}{|c|}{$\mathrm{Cr}_{2}(\text { Ind })_{2}(\text { allyl })_{2}$} & \multicolumn{2}{|c|}{$\mathrm{Cr}_{2}(\mathrm{Ind})_{4}$} & \multicolumn{2}{|c|}{$\mathrm{Cr}_{2}(\mathrm{Cp})_{2}(\mathrm{Ind})_{2}$} & \multicolumn{2}{|c|}{$\mathrm{Cr}_{2}(\mathrm{Cp})_{4}$} \\
\hline \multicolumn{2}{|c|}{ Exp. BL } & \multicolumn{2}{|c|}{$1.97(6)[14 b]$} & \multicolumn{2}{|c|}{$2.299(1)[12]$} & \multicolumn{2}{|c|}{$\begin{array}{c}2.171(1)-2.198(1) \\
{[12,13]}\end{array}$} & \multicolumn{2}{|c|}{$2.175(1)[10]$} & & & \\
\hline \multicolumn{2}{|c|}{ Computed spin state } & $S=0$ & $S=1$ & $S=0$ & $S=1$ & $S=0$ & $S=1$ & $S=0$ & $S=1$ & $S=0$ & $S=1$ & $S=0$ & $S=1$ \\
\hline \multirow{3}{*}{$B 3 L Y P$} & $B L$ & 1.860 & 2.023 & 2.038 & 2.197 & 1.941 & 2.123 & 1.910 & 2.118 & 1.880 & 1.936 & 1.901 & 2.058 \\
\hline & NPAI & 3.5 & 2.5 & 3.3 & 2.4 & 3.3 & 2.7 & 3.4 & 2.5 & 3.3 & 2.8 & 3.6 & 2.2 \\
\hline & $W I$ & 2.7 & 1.8 & 2.3 & 1.4 & 2.7 & 1.3 & 2.6 & 1.5 & 2.7 & 2.1 & 2.5 & 1.8 \\
\hline \multirow{3}{*}{$B 3 L Y P^{*}$} & $B L$ & 1.861 & 2.029 & 2.049 & 2.202 & 1.952 & 2.124 & 1.913 & 2.140 & 1.878 & 2.001 & 1.902 & 2.069 \\
\hline & NPAI & 3.5 & 2.7 & 3.3 & 2.4 & 3.5 & 2.5 & 3.3 & 2.4 & 3.3 & 2.7 & 3.4 & 2.7 \\
\hline & $W I$ & 2.6 & 2.0 & 2.3 & 1.4 & 2.4 & 1.6 & 2.3 & 1.7 & 2.7 & 2.1 & 2.6 & 1.8 \\
\hline \multirow{3}{*}{$B 3 L Y P-D$} & $B L$ & 1.860 & 2.029 & 2.028 & 2.157 & 1.947 & 2.110 & 1.895 & 2.105 & 1.872 & 2.998 & 1.998 & 2.077 \\
\hline & $N P A I$ & 3.4 & 2.5 & 3.5 & 2.4 & 3.0 & 2.5 & 3.4 & 2.6 & 3.4 & 2.7 & 3.3 & 2.7 \\
\hline & $W I$ & 2.6 & 1.8 & 2.2 & 1.5 & 2.4 & 1.6 & 2.5 & 1.7 & 2.6 & 2.0 & 2.6 & 1.7 \\
\hline \multirow{3}{*}{ BP86 } & $B L$ & 1.860 & 2.011 & 2.019 & 2.221 & 1.866 & 2.134 & 1.880 & 2.094 & 1.861 & 1.927 & 1.912 & 2.075 \\
\hline & $N P A I$ & 3.5 & 2.3 & 3.2 & 2.8 & 3.3 & 2.7 & 3.5 & 2.5 & 3.6 & 2.7 & 3.4 & 2.6 \\
\hline & $W I$ & 2.6 & 1.8 & 2.2 & 2.0 & 2.5 & 1.5 & 2.7 & 1.6 & 2.8 & 2.1 & 2.4 & 1.7 \\
\hline \multirow{3}{*}{ BP86-D } & $B L$ & 1.896 & 2.037 & 2.014 & 2.194 & 1.880 & 2.122 & 1.881 & 2.092 & 1.860 & 1.966 & 1.872 & 2.065 \\
\hline & NPAI & 3.3 & 2.5 & 3.2 & 2.3 & 3.6 & 2.5 & 3.4 & 2.4 & 3.4 & 2.7 & 3.3 & 2.5 \\
\hline & WI & 2.5 & 1.8 & 2.1 & 1.4 & 2.3 & 1.5 & 2.5 & 1.6 & 2.7 & 2.0 & 2.6 & 1.6 \\
\hline
\end{tabular}

\section{Investigation of the stability of related $M_{2}(I n d)_{4}$ and $M_{2}(C p)_{4}$ dimers.}

Starting from the fact that $\mathrm{Cr}_{2}$ (Ind $)_{4}$ exists with a metal-metal quadruple bond, one may wonder if other dimers with lower bond order might be reasonably stable. This is why the $\mathrm{M}_{2}(\mathrm{Ind})_{2}$ series, with $\mathrm{M}=\mathrm{Mn}, \mathrm{Fe}, \mathrm{Co}$, corresponding respectively to triple, double and single metal-metal bond order in the singlet state, has been investigated. For the sake of comparison the $\mathrm{M}_{2}(\mathrm{Cp})_{2}$ series has also been investigated. The major computed results are provided in Tables 3, 4 and S2. Both series of compounds exhibit similar trends and from the data of Table 3, it is difficult to predict with certainty that a particular dimer is isolable. On the other hand, the dimer of ferrocene is predicted unlikely to be isolated whatever is the functional used. Analysis of the electronic structures in their singlet states confirms the expected metal-metal bond orders of 3,2 and 1 for $\mathrm{Mn}, \mathrm{Fe}$ and $\mathrm{Co}$, respectively. However, the computed bond indices indicate rather weak bonds in the case of iron and cobalt. 
Table 3. Computed singlet/triplet or singlet/quintuplet free energy differences of the $\mathrm{M}_{2}(\mathrm{Ind})_{2}$ and $\mathrm{M}_{2}(\mathrm{Cp})_{2}(\mathrm{M}=\mathrm{Mn}, \mathrm{Fe}, \mathrm{Co})$ dimers and their free dissociation energy (formation of monomers; BSSE considered).

\begin{tabular}{|c|c|c|c|c|c|c|}
\hline & \multicolumn{2}{|c|}{$\mathrm{Mn}_{2}(\mathrm{Ind})_{4}$} & \multicolumn{2}{|c|}{$\mathrm{Fe}_{2}(\mathrm{Ind})_{4}$} & \multicolumn{2}{|c|}{$\mathrm{Co}_{2}(\mathrm{Ind})_{4}$} \\
\hline & $\Delta \mathrm{G}_{\mathrm{S} / \mathrm{T}}^{\mathrm{a}}$ & $\Delta \mathrm{G}_{\text {Diss }}^{\mathrm{b}}$ & $\Delta \mathrm{G}_{\mathrm{S} / \mathrm{T}}$ & $\Delta \mathrm{G}_{\text {Diss }}$ & $\Delta \mathrm{G}_{\mathrm{S} / \mathrm{T}}$ & $\Delta \mathrm{G}_{\text {Diss }}$ \\
\hline B3LYP & -4.7 & +8.5 & -16.0 & +1.0 & -15.6 & -12.1 \\
\hline B3LYP* & -2.4 & +1.0 & -17.5 & -2.9 & -4.0 & -9.0 \\
\hline B3LYP-D & -4.6 & -21.0 & -16.8 & -29.2 & -11.6 & -8.6 \\
\hline BP86 & +8.1 & -19.3 & -12.2 & -21.5 & +2.7 & -9.4 \\
\hline \multirow[t]{3}{*}{ BP86-D } & +7.9 & +6.2 & -12.6 & -8.2 & +4.4 & -5.4 \\
\hline & \multicolumn{2}{|c|}{$\mathrm{Mn}_{2}(\mathrm{Cp})_{4}$} & \multicolumn{2}{|c|}{$\mathrm{Fe}_{2}(\mathrm{Cp})_{4}$} & \multicolumn{2}{|c|}{$\mathrm{Co}_{2}(\mathrm{Cp})_{4}$} \\
\hline & $\Delta \mathrm{G}_{\mathrm{S} / \mathrm{Q}}^{\mathrm{c}}$ & $\Delta \mathrm{G}_{\text {Diss }}$ & $\Delta \mathrm{G}_{\mathrm{S} / \mathrm{T}}$ & $\Delta \mathrm{G}_{\text {Diss }}$ & $\Delta \mathrm{G}_{\mathrm{S} / \mathrm{T}}$ & $\Delta \mathrm{G}_{\text {Diss }}$ \\
\hline B3LYP & +31.5 & +3.9 & -21.3 & -17.7 & -13.3 & +4.3 \\
\hline B3LYP* & +24.6 & +9.3 & -6.6 & -11.7 & -8.1 & -1.0 \\
\hline B3LYP-D & +36.6 & -19.9 & -9.1 & -27.9 & -11.3 & -9.9 \\
\hline BP86 & +12.9 & -17.2 & -8.2 & -22.0 & +10.6 & -25.1 \\
\hline BP86-D & +8.6 & -1.4 & -9.7 & -19.7 & +5.9 & +1.5 \\
\hline
\end{tabular}

${ }^{\mathrm{a}} \Delta \mathrm{G}_{\mathrm{S} / \mathrm{T}}=\mathrm{G}$ (singlet) $-\mathrm{G}$ (triplet) and $\Delta \mathrm{G}_{\mathrm{S} / \mathrm{Q}}=\mathrm{G}($ singlet $)-\mathrm{G}$ (quintuplet), (in kcal $\left./ \mathrm{mol}\right)$. A negative value means singlet ground state.

${ }^{\mathrm{b}} \Delta \mathrm{G}_{\text {Diss }}=2 \times \mathrm{G}$ (monomer ground state) $-\mathrm{G}$ ( dimer ground state) (in $\left.\mathrm{kcal} / \mathrm{mol}\right)$. A negative value means that the compound is more stable in its monomer form.

${ }^{\mathrm{c}}$ The lowest high-spin state computed for $\mathrm{Mn}_{2}(\mathrm{Cp})_{2}$ is a quintuplet. 
Table 4. Computed M-M bond lengths (BL, in $\AA$ ) for the $\mathrm{M}(\mathrm{Ind})_{4}$ models $(\mathrm{M}=\mathrm{Mn}, \mathrm{Fe}, \mathrm{Co})$ and corresponding computed NPA and Wiberg bond indices (NPAI and WI, respectively; see Computational Details).

\begin{tabular}{|c|c|c|c|c|c|c|c|}
\hline & & \multicolumn{2}{|c|}{$\mathrm{Mn}_{2}(\mathrm{Ind})_{4}$} & \multicolumn{2}{|c|}{$\mathrm{Fe}_{2}(\mathrm{Ind})_{4}$} & \multicolumn{2}{|c|}{$\mathrm{Co}_{2}(\mathrm{Ind})_{4}$} \\
\hline & $\begin{array}{l}\text { Spin } \\
\text { state }\end{array}$ & $S=0$ & $S=1$ & $\mathrm{~S}=0$ & $S=1$ & $\mathrm{~S}=0$ & $\mathrm{~S}=1$ \\
\hline \multirow{3}{*}{ B3LYP } & $\mathrm{BL}$ & 2.003 & 2.134 & 2.522 & 3.161 & 2.588 & 3.364 \\
\hline & NPAI & 2.3 & 2.4 & 1.0 & 0.1 & 0.7 & 0.2 \\
\hline & WI & 1.7 & 1.8 & 0.8 & 0.1 & 0.5 & 0.2 \\
\hline \multirow{3}{*}{ B3LYP* } & $\mathrm{BL}$ & 2.015 & 2.325 & 2.458 & 2.943 & 2.622 & 2.985 \\
\hline & NPAI & 2.4 & 1.1 & 1.0 & 0.1 & 1.0 & 0.8 \\
\hline & WI & 1.7 & 1.0 & 0.6 & 0.1 & 0.7 & 0.7 \\
\hline \multirow{3}{*}{ B3LYP-D } & $\mathrm{BL}$ & 1.987 & 2.126 & 2.321 & 3.027 & 2.532 & 3.008 \\
\hline & NPAI & 2.3 & 1.9 & 1.2 & 0.7 & 1.0 & 0.7 \\
\hline & WI & 1.6 & 1.6 & 0.8 & 0.4 & 0.7 & 0.6 \\
\hline \multirow{3}{*}{ BP86 } & $\mathrm{BL}$ & 2.041 & 2.182 & 2.399 & 2.349 & 2.626 & 2.559 \\
\hline & NPAI & 2.5 & 2.8 & 1.2 & 0.9 & 0.7 & 0.8 \\
\hline & WI & 1.7 & 1.8 & 0.8 & 0.8 & 0.5 & 0.6 \\
\hline \multirow{5}{*}{ BP86-D } & BL & 2.033 & 2.170 & 2.309 & 2.293 & 2.553 & 2.401 \\
\hline & NPAI & 2.5 & 2.4 & 1.3 & 1.3 & 0.7 & 0.8 \\
\hline & WI & & 1.8 & 0.7 & 0.8 & 0.5 & 0.6 \\
\hline & & \multicolumn{2}{|c|}{$\mathrm{Mn}_{2}(\mathrm{Cp})_{4}$} & \multicolumn{2}{|c|}{$\mathrm{Fe}_{2}(\mathrm{Cp})_{4}$} & \multicolumn{2}{|c|}{$\mathrm{Co}_{2}(\mathrm{Cp})_{4}$} \\
\hline & $\begin{array}{l}\text { Spin } \\
\text { state }\end{array}$ & $\mathrm{S}=0$ & S & $\mathrm{s}$ & $S=$ & $\mathrm{S}=0$ & $S=1$ \\
\hline \multirow{3}{*}{ B3LYP } & $\mathrm{BL}$ & 2.216 & 2.433 & 2.522 & 3.161 & 2.603 & 2.869 \\
\hline & NPAI & 2.8 & 0.9 & 1.0 & 0.07 & 1.2 & 0.8 \\
\hline & WI & 1.94 & 0.2 & 0.8 & 0.06 & 0.5 & 0.7 \\
\hline \multirow{3}{*}{ B3LYP* } & BL & 2.037 & 2.797 & 2.458 & 2.943 & 2.558 & 2.611 \\
\hline & NPAI & 2.8 & 0.7 & 1.0 & 0.06 & 1.2 & 1.2 \\
\hline & WI & 2.0 & 0.1 & 0.6 & 0.1 & 0.7 & 0.9 \\
\hline \multirow{3}{*}{ B3LYP-D } & $\mathrm{BL}$ & 2.083 & 2.660 & 2.321 & 3.027 & 2.491 & 2.742 \\
\hline & NPA & 2.8 & 0.8 & 1.2 & 0.7 & 1.2 & 0.8 \\
\hline & WI & 1.9 & 0.3 & 0.8 & 0.4 & 0.7 & 0.7 \\
\hline \multirow{3}{*}{ BP86 } & BL & 2.034 & 2.484 & 2.399 & 2.349 & 2.551 & 2.438 \\
\hline & NPAI & 2.5 & 1.0 & 1.2 & 0.9 & 1.2 & 1.5 \\
\hline & WI & 2.1 & 0.2 & 0.8 & 0.8 & 0.8 & 1.0 \\
\hline \multirow{3}{*}{ BP86-D } & $\mathrm{BL}$ & 2.043 & 2.404 & 2.309 & 2.293 & 2.489 & 2.526 \\
\hline & NPAI & 2.5 & 1.0 & 1.3 & 1.3 & 1.2 & 1.2 \\
\hline & WI & 2.1 & 0.2 & 0.7 & 0.8 & 0.8 & 1.0 \\
\hline
\end{tabular}

\section{Conclusion}

The elusive electron-deficient $\operatorname{Cr}\left(\eta^{5} \text {-Ind }\right)_{2}$ sandwich monomer possesses six formal 2electron metal-ligand bonds. Its dimerization in $\mathrm{Cr}_{2}\left(\eta^{5}-\mathrm{Ind}\right)_{2}\left(\mu-\eta^{3}-\mathrm{Ind}\right)_{2}$ allows each metal center to build four $\mathrm{Cr}-\mathrm{Cr}$ bonds (in the singlet state) whereas it still participates in five formal 2electron metal-ligand bonds. Thus, in terms of bonding the balance of dimerization appears very positive at first sight. However, one has to consider that in general a 2-electron metal-metal bond 
is substantially weaker than a metal-ligand bond, especially in the case of first-row metals. One has also to consider that the crowding of the ligands around the two metal centers tends to destabilize the dimer. The preference of aromatic 5-fold rings for $\eta^{5}$ - rather than $\eta^{3}$-coordination (even in the case of indenyl, although less pronounced than for cyclopentadienyl) has also to be considered. It results that the energetic balance in favour of the dimer is not very large. This is why $\mathrm{Cr}_{2}$ (Ind) $)_{4}$ appears as unique in the series of the related complexes that we have computed. In the case of hypothetical cyclopentadienyl-containing dimers, one has to consider that metalcyclopentadienyl bonding is stronger than metal-indenyl bonding and thus tends to weaken M-M bonding, rendering dimerization less favourable. Nevertheless, dimers such as $\mathrm{Cr}_{2}(\mathrm{Cp})_{2}(\mathrm{Ind})_{2}$, $\mathrm{Cr}_{2}(\mathrm{Cp})_{4}$ (the dimer of chromocene) or $\mathrm{Mn}_{2}(\mathrm{Ind})_{4}$ appear to be not that much unstable relatively to their monomer for being observed under some specific circumstances.

\section{Supporting Information}

Kohn-Sham orbital diagram of $\mathrm{Cr}_{2} \mathrm{Cp}_{2}(\text { allyl })_{2}$ and $\mathrm{Cr}_{2} \mathrm{Cp}_{4}$ (Figure S1). Computed lowspin/high-spin energy differences of the investigated dinuclear complexes and their free dissociation energy (Tables S1 and S2). A text file of the optimized geometries in Mol format.

\section{Acknowledgements}

The GENCI-CINES and GENCI-IDRISS French national computer centers are acknowledged for computational resources (A0010807367). BZ is grateful to the DGRS-DT for the financial support. 


\section{REFERENCES}

[1] (a) M.E. Rerek, F. Basolo, J. Am. Chem. Soc. 106 (1984) 5908-5912; (b) J. M. O'Connor, C.P. Casey, Chem. Rev. (1987) 307-318; (c) H. Sitzmann, Coord. Chem. Rev. 214 (2001) 287327; (d) F.G.N. Cloke, Pure Appl. Chem. 73 (2001) 233-238; (e) O.T. Summerscales, F.G.N. Cloke, Coord. Chem. Rev. 250 (2006) 1122-140; (f) M.J. Calhorda, V. Félix, L.F. Veiros, Coord. Chem. Rev. 230 (2002) 49-64; (g) D. Zargarian Coord. Chem. Rev. 233 (2002) 157; (h) R.B. King, Appl. Organometal. Chem. 17 (2003) 393-397; (i) M. Stradiotto, M.J. McGlinchey, Coord. Chem. Rev. (2004) 219-221, 311-378; (j) A. Ceccon, S. Santi, L. Orian, A. Bisello, Coord. Chem. Rev. 248 (2004) 683-724; (k) P.J. Chirik, Organometallics 29 (2010) 1500-1517.

[2] (a) C.A. Bradley, I. Keresztes, E. Lobkovsky, V.G. Young, P.J. Chirik, J. Am. Chem. Soc. 126 (2004) 16937-16950; (b) C.A. Bradley, L.F.D. Veiros, Pun, E. Lobkovsky, I Keresztes, P.J. Chirik, J. Am. Chem. Soc. 128 (2006) 16600-16612; (c) C.A. Bradley, L.F. Veiros, P.J. Chirik,. Organometallics 26 (2007) 3191-3200.

[3] (a) J.A. Crisp, M.B. Meredith, T. P. Hanusa, G. Wang, W.W. Brennessel, W.W. Yee, G.T. Inorg. Chem. 44 (2005) 172-174; (b) J.A. Crisp, R.M. Meier, J.S. Overby, T.P. Hanusa, A.L. Rheingold, W.W. Brennessel, Organometallics. 2010, 29, 2322-2331.

[4] D. O’Hare, V. J. Murphy, N. Kaltsoyannis, Dalton Trans. (1993) 383-392.

[5] (a) J.S. Overby, T.P. Hanusa, S.P. Sellers, G.T. Yee, Organometallics 18 (1999) 3561-3562; (b) E.D. Brady, J.S. Overby, M.B. Meredith, A.B. Mussman, M.A. Cohn, T.P. Hanusa, G.T. Yee, M. Pink, J. Am. Chem. Soc. 124 (2002) 9556-9566; (c) M.B. Meredith, J.A. Crisp, E.D. Brady, T.P. Hanusa, G.T. Yee, N.R. Brook, B.E. Kucera, V.G. Young Jr, Organometallics 25 (2006) 4945-4952; (d) M.B. Meredith, J.A. Crisp, E.D. Brady, T.P. Hanusa, G.T. Yee, M. Pink, W.W. Brennessel, V.G. Young Jr, Organometallics 27 (2008) 5464-5473.

[6] S.A. Westcott, A.K. Kakkar, G. Stringer, N.J. Taylor, T.B. Marder, J. Organomet. Chem. 394 (1990) $777-794$.

[7] (a) G.M. Fern, S. Klaib, O.J. Curnow, H. Lang, J. Organomet. Chem. 689 (2004) 1139-1144;

(b) G.M. Fern, O.J. Curnow, J. Organomet. Chem. 690 (2005) 3018-3026.

[8] S. Guo, I. Balog, R. Hauptmann, M. Nowotny, J.J. Schneider, J. Organomet. Chem. 694 (2009) 1027-1035. 
[9] F. Chekkal, S.-M. Zendaoui, B. Zouchoune, J.-Y. Saillard, New J. Chem.37 (2013) 22932302.

[10] O. Heinemann, P.W. Jolly, C. Krüger, G.P.J. Verhovnik, Organometallics 15 (1996) 54625463.

[11] (a) F.A. Cotton, C.A. Murillo, R.A. Walton, Multiple Bonds Between Metal Atoms; Springer: New York, 2005; (b) J. Losada, S. Alvarez, J.J. Novoa, F. Mota, R. Hoffmann, J. Silvestre, J. Am. Chem. Soc. 112 (1990) 8998-9000.

[12] P. Betz, A. Döhring, R. Emrich, R. Goddard, P.W. Jolly, C. Krüger, C.C. Romão, K.U. Schönfelder, Y.H. Tsay, Polyhedron. 12 (1993) 2651-2662.

[13] Two independent molecules in the unit cell of this compound (see ref. 11).

[14] (a) R Benn, Angew. Chem. 94 (1982) 633-634; (b) T. Aoki, A. Furusaki, Y. Tomiie, K. Ono, K. Tanaka, Bull. Chem. Soc. Jpn. 42 (1969) 545-547.

[15] J. Nieman, J.W. Pattiasina, J.H. Teuben, J. Organomet. Chem. 262 (1984) 157-169.

[16] (a) G. La Macchia, F. Aquilante, V. Veryazov, B.O. Roos, L. Gagliardi, Inorg. Chem. 47 (2008) 11455-11457; (b) G. La Macchia, G. Li Manni, T. K. Todorova, M. Brynda, F. Aquilante, B.O. Roos, L. Gagliardi, Inorg. Chem. 49 (2010) 5216-5222.

[17] S. Ndambui, T. Ziegler, Inorg. Chem. 52 (2013) 3860-3869; (b) Z. Sun, H.F. Schaefer, Y. Xie, Y. Liu, R. Zhong, Mol. Phys. 111 (2013) 2523-2535. (c) A. Falceto, K.H. Theopold, S. A1varez, Inorg. Chem. 54 (2015) 10966-10977.

18 (a) ADF2014.01, Theoretical Chemistry, Vrije Universiteit: Amsterdam, The Netherlands, SCM; (b) E.J. Baerends, D.E. Ellis, P. Ros, Chem. Phys. 2 (1973) 41-51, (c) G. te Velde, E.J. Baerends, J. Comput. Phys. 99 (1992) 84-98 ; (d) C. Fonseca Guerra, J.G. Snijders, G. te Velde, E.J. Baerends, Theor. Chim. Acc. 99 (1998) 391-403; (e) F.M. Bickelhaupt, E.J. Baerends, Rev. Comput. Chem. 15 (2000) 1-86; (f) G. te Velde, F.M. Bickelhaupt, C. Fonseca Guerra, S.J.A. van Gisbergen, E.J. Baerends, J.G. Snijders, T. Ziegler, J. Comput. Chem. 22 (2001) 931-967.

[19] S.D. Vosko, L. Wilk, M. Nusair, Can. J. Chem. 58 (1990) 1200-1211.

[20] (a) A.D. Becke, J. Chem. Phys. 84 (1986) 4524-4529; (b) A.D. Becke, Phys. Rev. A 38 (1988) 3098-3100; (c) J.P. Perdew, Phys. Rev. B 33 (1986) 8822-8824, (d) J.P. Perdew, Phys. Rev. B 34 (1986) 7406-7406.

[21] (a) A.D. Becke, Chem. Phys. 98 (1993) 5648-5652; (b) C. Lee, W. Yang, R.G. Parr, Phys.Rev. B 37 (1988) 785-789. 
[22] O. Salomon, M. Reiher, A. Hess, J. Chem. Phys. 117 (2002) 4729-4737.

[23] S. Grimme, WIREs Comput. Mol. Sci. 1 (2011) 211-228.

[24] E. van Lenthe, A.W. Ehlers, E.J. Baerends, J. Chem. Phys. 110 (1999) 8943-8954.

[25] L. Versluis, T. Ziegler, J. Chem. Phys. 88 (1988) 322-327.

[26] (a) L. Fan, T. Ziegler, J. Chem. Phys. 96 (1992) 9005-9012; (b) L. Fan, T. Ziegler, J. Phys. Chem. 96 (1992) 6937-6941.

[27] P. Flükiger, H. P. Lüthi, S. Portmann, J. Weber, MOLEKEL, Version 4.3.win32, Swiss Center for Scientific Computing (CSCS), Switzerland, 2000-2001. http://www.cscs.ch/molekel/.

[28] K.B. Wiberg, Tetrahedron. 24 (1968) 1083-1084.

[29] (a) F. Weinhold, C.R. Landis, Valency and Bonding: a Natural Bond Order Donor Acceptor Perspective, Cambridge University Press, U. K., 2005; (b) E.D. Glendening, J.K. Badenhoop, A.E. Reed, J.E. Carpenter, J.A. Bohmann, C.M. Morales, C.R. Landis, F. Weinhold, NBO 6.0.; Theoretical Chemistry Institute, University of Wisconsin: Madison, 2013. www.chem.wisc.edu/_nbo6. 
- The existence of a $\mathrm{Cr}-\mathrm{Cr}$ quadruple allows stabilizing bis-indenylchromium.

- The peculiar nature of the indenyl ligand favors dimerization.

- The dimer of chromocene is a not so high energy minimum. 